\title{
Glycerol (Byproduct of Biodiesel Production) as a Source for Fuels and Chemicals - Mini Review
}

\author{
Xiaohu Fan ${ }^{*}$, , Rachel Burton ${ }^{1}$ and Yongchang Zhou ${ }^{2}$ \\ ${ }^{I}$ Piedmont Biofuels Industrial, Pittsboro, NC 27312, USA \\ ${ }^{2}$ Yonezawa Hamari Chemical, Ltd, Yonezawa-city, Yamagata, Japan
}

\begin{abstract}
Currently the large surplus of glycerol formed as a by-product during the production of biodiesel offered an abundant and low cost feedstock. Researchers showed a surge of interest in using glycerol as renewable feedstock to produce functional chemicals. This Minireview focuses on recent developments in the conversion of glycerol into valueadded products, including citric acid, lactic acid, 1,3-dihydroxyacetone (DHA), 1,3-propanediol (1,3-PD), dichloro-2propanol (DCP), acrolein, hydrogen, and ethanol etc. The versatile new applications of glycerol in the everyday life and chemical industry will improve the economic viability of the biodiesel industry.
\end{abstract}

Keywords: Biodiesel, glycerol, feedstock, value-added product.

\section{INTRODUCTION}

As the most viable alternative fuel, biodiesel has received an attractive attention during the past few years because of the dwindling petroleum reserves and the associated environmental impacts from the usage of fossil fuels. Although biodiesel represents a secure, renewable and environmentally safe alternative to fossil fuels, its economic viability is a major concern. At the same time, the increased production of biodiesel influenced remarkably the glycerol market due to the generation of a glut of crude glycerol, the by-product of biodiesel production, which is yielded at about $10 \%(\mathrm{wt} / \mathrm{wt})$ of biodiesel during the process of biodiesel production. The global biodiesel market is estimated to reach 37 billion gallons by 2016 with an average annual growth of $42 \%$, which means about 4 billion gallons of crude glycerol will be produced [1]. The glycerol price has plummeted over the last few years due to the over supply. Therefore, it is imperative to find alternative uses for glycerol. Glycerol has many uses in different industries, such as food, paint, pharmaceutical, cosmetic, soap, toothpaste, etc, but its surplus is dramatically increasing, so new applications should be developed. The increasing abundance and attractive pricing of glycerol make this product an appealing source of chemical to derive value-added commercial compounds. Many researchers showed strong interest in this area. It was reported that many high-value chemicals could be achieved by using glycerol as raw material, such as citric acid, lactic acid, DHA, DCP, hydrogen, ethanol, etc.

In this Minireview, the recent developments in the conversion of glycerol into value-added chemicals were described. Throughout this Minireview, examples of possible production processes based on glycerol demonstrate that glycerol is a promising abundant source which could improve the economic viability of the biodiesel industry.

*Address correspondence to this author at the Piedmont Biofuels Industrial, 220 Lorax Lane, P.O.Box 661, Pittsboro, NC 27312, USA; Tel: 919-3218260; Fax: 919-321-6769; E-mail: xfan@biofuels.coop

\section{GLYCEROL TO CHEMICALS AND MATERIALS}

\subsection{Glycerol to Citric Acid}

Citric acid has a variety of applications. As a food additive, citric acid is used as a flavoring and preservative in food and beverages, especially soft drinks. It can also be utilized as an additive in cosmetics, toiletries, and pharmaceuticals. Citric acid is mainly produced by submerged fungal fermentation of sucrose or molasses medium using Aspergillus niger. Many researchers showed interests in using inexpensive raw material to industrially produce citric acid, including crude glycerol. Rymowicz et al. [2] examined the potential for citric acid biosynthesis by three acetate mutants of the yeast species Yarrowia lipolytica, including Strain K-1, Strain AWG-7, and Strain 1.31 , under batch cultivation conditions on raw glycerol. The experimental results demonstrated that the strain Y. lipolytica 1.31 was the most suitable for citric acid production. Using this strain, the citric acid production of $124.5 \mathrm{~g} \mathrm{dm}^{-3}$, yield of $0.62 \mathrm{~g} \mathrm{~g}^{-1}$, and productivity of $0.88 \mathrm{~g} \mathrm{dm}^{-3} \mathrm{~h}^{-1}$ could be obtained at the initial concentration of glycerol of $200 \mathrm{~g} \mathrm{dm}^{-3}$. Imandi et al. [3] also investigated the yeast species Yarrowia lipolytica for producing citric acid from crude glycerol. The authors optimized citric acid production by Yarrowia lipolytica NCIM 3589 in submerged fermentation using crude glycerol. Yeast extract, raw glycerol, and salt solution concentration were statistically analyzed using response surface methodology involving Doehlert experimental design to evaluate the amount of citric acid produced. The maximum citric acid concentration of $77.3999 \mathrm{~g} / \mathrm{l}$ was obtained at the optimal conditions, that is, yeast extract $0.2682 \mathrm{~g} / \mathrm{l}$, raw glycerol $54.4081 \mathrm{~g} / \mathrm{l}$, and salt solution concentration $13.6936 \%(\mathrm{v} / \mathrm{v})$.

\subsection{Glycerol to Lactic Acid}

The salts and esters of lactic acid show versatile applications in the fields of the industrial, food, cosmetic and pharmaceutical industries and agriculture [4]. Hong et al. [5] conducted the study of some fundamental problems of lactic 
acid production from glycerol, aiming at to select a strain suitable for producing high concentration and productivity of lactic acid from glycerol. Among the eight bacterial strains investigated, the strain AC-521, a member of Escherichia coli, was found to be the most suitable one for lactic acid production from glycerol based on its $16 \mathrm{~S}$ rDNA sequences and physiological characteristics. Optimal fermentation conditions were deduced: $42{ }^{\circ} \mathrm{C}, \mathrm{pH} 6.5$, and $0.85 \mathrm{~min}^{-1}$ $\left(\mathrm{K}_{\mathrm{L}} \mathrm{a}\right)$. Maximum lactic acid concentration and glycerol consumption were reached after $88 \mathrm{~h}$ of fed-batch fermentation, achieving a yield of $0.9 \mathrm{~mol} \mathrm{~mol}^{-1}$ glycerol and $85.8 \mathrm{~g} \mathrm{~L}^{-1}$ of lactic acid with a productivity of $0.97 \mathrm{~g} \mathrm{~L}^{-1} \mathrm{~h}^{-1}$.

\subsection{Glycerol to 1,3-Dihydroxyacetone (DHA)}

DHA is an important chemical used in the cosmetics industry as a tanning substance and also in fungicides. Ciriminna et al. [6] reported that DHA could be obtained by one-pot electrocatalytic oxidation of glycerol. In their study, a small electric potential $(1.1 \mathrm{~V} v s \mathrm{Ag} / \mathrm{AgCl})$ was applied to a glycerol solution in water buffered at $\mathrm{pH} 9.1$ in the presence of $15 \mathrm{~mol} \%$ 2,2,6,6-tetramethylpiperidine-1-oxyl. Pyle et al. [7] produced DHA through fermentation of the alga Schizochytrium limacinum on crude glycerol and found that the crude glycerol-derived algal biomass contained a high level of DHA. Meanwhile, the authors investigated the effects of impurities, including methanol and soap, on DHA production and algal biomass composition. The experimental results showed that both methanol and soap had negative impact on algal DHA production. The inhibitory effect of soap on $S$. limacinum was attributed to the complex interaction between the cell wall/membrane and the soap. Fortunately, these two impurities can be removed from culture medium by evaporation through autoclaving (for methanol) and by precipitation through $\mathrm{pH}$ adjustment (for soap).

\subsection{Glycerol to 1,3-Propanediol}

1,3-propanediol (1,3-PD) has a variety of applications in polymers, cosmetics, foods, lubricants, and medicines. $\mathrm{Mu}$ et al. [8] performed shake-flask and fed-batch fermentations by Klebsiella pneumoniae to produce 1,3-PD using both pure glycerol and crude glycerol derived from methanolysis of soybean oil. It was reported that the 1,3-PD concentration of $51.3 \mathrm{~g} / 1$ on crude glycerol from alkali-catalyzed methanolysis of soybean oil was achieved, which was comparable to that of $53 \mathrm{~g} / \mathrm{l}$ on crude glycerol derived from a lipase-catalyzed process. Furthermore, it was found that the productivities of $1.7 \mathrm{~g} \mathrm{l}^{-1} \mathrm{~h}^{-1}$ on crude glycerol were comparable to that of $2 \mathrm{~g} \mathrm{l}^{-1} \mathrm{~h}^{-1}$ on pure glycerol. As comparison, Németh et al. [9] developed a coenzymeregenerating enzymatic bioconversion in a membrane reactor for the production of 1,3-PD using the crude key enzymes of Klebsiella pneumoniae. After $24 \mathrm{~h}$, the conversion of $88 \%$ was achieved and the reaction mixture contained $46 \% 1,3-$ PD, $10 \%$ DHA, and $15 \%$ acetic acid. However, some byproducts also formed during successful bioconversion of glycerol to 1,3-PD. It was concluded that this problem can only be solved by using Clostridium butyricum VPI1718 since in its microorganism glycerol dehydratase enzyme does not need adenosine triphosphate-dependent regeneration. Other researchers investigated the use of this speicies, Clostridium butyricum DSM 5431, for the production of 1,3-PD from glycerol obtained during methanolysis of sunflower oil [10]. Based on their study, this process was feasible only that pretreated crude glycerol was used due to the inability of Clostridium butyricum DSM 5431 to withstand the inhibitory effects of high concentrations of oleic acid and linoleic acid.

\subsection{Glycerol to Dichloro-2-Propanol (DCP)}

The synthesis of DCP is important since it is an intermediate in the production of epichlorohydrin [11], which is an intermediate in the production of epoxide resins, glycerine, and several pharmaceutical products [12]. Recently Luo et al. [13] experimentally and theoretically investigated the direct preparation of DCP from glycerol using acetic acid catalyst in a batch reactor at 363-393 K. The experiment showed that the glycerol decreased to its minimum at about 100 minutes and remained nearly unchanged after that. In the period of 0-100 minutes, the concentration of glycerol decreased very quickly and the concentration of 3-chloro-1,2-propanediol (MCP), which was later verified to be the intermediate, increased quickly. It was found that the direct preparation mechanism of DCP from glycerol followed second-order nucleophilic substitution mechanism. Instead of using acetic acid, Lee et al. [14] evaluated the use of heteropolyacid (HPA) for direct preparation of DCP from glycerol. It was found that the selectivity for DCP increased with increasing acid strength of the catalyst. Among the catalysts tested, $\mathrm{H}_{3} \mathrm{PW}_{12} \mathrm{O}_{40}$ catalyst with the highest acid strength demonstrated the best catalytic performance, indicating the important role the acid strength of HPA played in determining the catalytic performance in the direct preparation of DCP from glycerol.

\subsection{Glycerol to Acrolein}

As the simplest unsaturated aldehyde, acrolein has a variety of uses: major feedstock for 1,3-propanediol; as a microbiocide in oil wells, liquid hydrocarbon fuels, water treatment ponds, and as a slimicide in the manufacture of paper. Acrolein can also be used to synthesize acrylic acid and its lower alkyl ester and DL-methionine. Watanabe et al. [15] synthesized acrolein from glycerol in hot-compressed water using a batch and a flow apparatus. They reported that the rate constant of acrolein decomposition was always higher than that of acrolein formation, which could be overcome by adding acid catalyst. It was found that $74 \mathrm{~mol} \%$ of acrolein yield and $81 \%$ of its selectivity was obtained with acid catalyst in supercritical condition $(673 \mathrm{~K}, 34.5 \mathrm{MPa})$. Yan et al. [16] conducted a study using low-pressure packedbed gas-phase dehydration of glycerol to produce acrolein. The authors reported the following important findings: Pressure had a significant influence on the carbon deposit. Lower pressures are effective for rapidly removing the more volatile products from the catalyst sites, achieving a long catalyst service life; Reaction temperature showed no significant influence on the selectivity of acrolein; Low glycerol concentration in the feed can enhance the catalyst's selectivity of glycerol to acrolein since high initial glycerol content can result in glycerol polymerization, which occurred on the catalyst sites. By using the fractional factorial design and statistical analysis, it was concluded that $66.8 \%$ of acrolein yield and $84 \%$ of its selectivity could be 
achieved at the temperature of $260{ }^{\circ} \mathrm{C}$ and 0.85 bar in the presence of $\mathrm{H}_{3} \mathrm{PO}_{4} /$ activated carbon catalyst.

\section{GLYCEROL TO FUELS AND FUELS ADDITIVE}

\subsection{Glycerol to Hydrogen}

Glycerol can be converted into hydrogen in each of the following process: Steam reforming, partial oxidation, autothermal reforming, aqueous-phase reforming, and supercritical water reforming.

\subsubsection{Steam Reforming}

The steam reforming is a high temperature endothermic process which uses a catalyst to react the glycerol with water to produce hydrogen. The overall reaction of hydrogen production by steam reforming of glycerol $\left(\mathrm{C}_{3} \mathrm{H}_{8} \mathrm{O}_{3}\right)$ could be depicted as follows: $\mathrm{C}_{3} \mathrm{H}_{8} \mathrm{O}_{3}(\mathrm{~g})+3 \mathrm{H}_{2} \mathrm{O}(\mathrm{g}) \rightarrow 7 \mathrm{H}_{2}(\mathrm{~g})+$ $3 \mathrm{CO}_{2}(\mathrm{~g})$. Wang et al. [17] studied thermodynamic properties of glycerin reforming with the method of Gibbs free energy minimization for hydrogen and/or synthesis gas production. They concluded that high temperature, low pressure, and high water/glycerin ratio favor hydrogen production. Optimal conditions for hydrogen production from glycerin were found to be at a temperature of $925-975 \mathrm{~K}$ and a water/glycerin ratio of 9-12 at atmospheric pressure. At 925 $\mathrm{K}$ and $\mathrm{a}$ water/glycerin ratio of 12 under atmospheric pressure, the maximum number of 6.2 moles of hydrogen can be produced with per mole of glycerin. Similar results were reported by Adhikari et al. [18], who concluded that the best condition for producing hydrogen were at $>900 \mathrm{~K}$ temperature, atmospheric pressure, and 9/1 of water/glycerin molar ratio. They explained that under these conditions, methane production is minimized and the carbon formation is thermodynamically inhibited. The viability of using steam reforming to produce hydrogen from biodiesel by-product glycerol was also confirmed by Slinn et al. [19]. The authors preferred using $\mathrm{Pt} / \mathrm{Al}_{2} \mathrm{O}_{3}$ as catalysts. Optimum reformer performance was reached at $880{ }^{\circ} \mathrm{C}$, flow rate of 0.12 $\mathrm{mols} / \mathrm{min}$ (glycerol) per $\mathrm{kg}$ catalyst, and steam/carbon ratio of 2.5. However, under the same reaction conditions, the yield of by-product glycerol was on average $30 \%$ less than pure glycerol. The researchers attributed this by the fact that the long chain fatty acid impurities are harder to reform and more likely to form carbon.

Many researchers investigated the effects of catalysts on the steam reforming of glycerol for hydrogen production. Adhikari et al. [20] focused on the study of nickel-based catalysts with $\mathrm{MgO}, \mathrm{CeO}_{2}$, and $\mathrm{TiO}_{2}$ supports. They found maximum hydrogen yield, that is, $4 \mathrm{~mol}$ of $\mathrm{H}_{2}$ out of $7 \mathrm{~mol}$ of stoichiometric maximum, could be obtained at $650{ }^{\circ} \mathrm{C}$ with $\mathrm{MgO}$ supported catalysts. Iriondo et al. [21] modified alumina-supported nickel catalysts with $\mathrm{Ce}, \mathrm{Mg}, \mathrm{Zr}$ and $\mathrm{La}$ to produce hydrogen from glycerol. They found the use of $\mathrm{Ce}, \mathrm{La}, \mathrm{Mg}$ and $\mathrm{Zr}$ as promoters of $\mathrm{Ni}$ based catalysts increases the hydrogen selectivity, which was shown as higher $\mathrm{H}_{2}$ and $\mathrm{CO}_{2}$ yields and lower $\mathrm{CO}$ yield. The authors further deduced that $\mathrm{Ce}$ and $\mathrm{La}$ can increase stability of nickel phases under reaction conditions; $\mathrm{Mg}$ can enhance surface nickel concentration; $\mathrm{Zr}$ can improve the capacity to activate steam.

Besides nickel based catalysts, other types of catalysts were also evaluated for steam reforming of glycerol. Ceria- supported $\mathrm{Ir}$, Co and $\mathrm{Ni}$ catalysts have been studied by Zhang et al. [22]. All the ceria-based catalysts investigated exhibited significant activity and selectivity since the dehydration of glycerol to ethylene or propylene didn't occur, which can cause coke formation and deactivate the catalysts. Among the ceria-supported metal catalysts examined, the $\mathrm{Ir} / \mathrm{CeO}_{2}$ catalyst showed promising catalytic performance with more than $85 \%$ hydrogen selectivity and $100 \%$ glycerol conversion at $400{ }^{\circ} \mathrm{C}$. As comparison, Hirai et al. [23] developed a novel efficient catalyst for steam reforming of glycerin. Ruthenium catalysts were preferred and high performance was observed for the $\mathrm{Ru} / \mathrm{Y}_{2} \mathrm{O}_{3}$ catalysts.

\subsubsection{Partial Oxidation}

Partial oxidation is the process in which a substrate is reacted with oxygen at sub-stoichiometric ratios. The process can be depicted as follows:

Substrate $\left(\mathrm{C}_{\mathrm{n}} \mathrm{H}_{\mathrm{m}} \mathrm{O}_{\mathrm{p}}\right)+$ air $\rightarrow$ carbon oxides + hydrogen + nitrogen

Dauenhauer et al. [24] performed glycerol oxidation at different carbon-to-oxygen $(\mathrm{C} / \mathrm{O})$ ratios and temperatures using noble metal catalysts. Partial oxidation of glycerol at reactant steam-to-carbon ratio $(\mathrm{S} / \mathrm{C})=0$ achieved equilibrium $\mathrm{H}_{2}$ selectivity for all $\mathrm{C} / \mathrm{O}$ ratios $<1.3$ with a maximum of $56 \%$ at $\mathrm{C} / \mathrm{O}=1.2$.

\subsubsection{Autothermal Reforming}

Autothermal reforming process combines the effect of partial oxidation and steam reforming by feeding fuel, air, and water together into the reactor. The process can be shown as follows:

Substrate $\left(\mathrm{C}_{\mathrm{n}} \mathrm{H}_{\mathrm{m}} \mathrm{O}_{\mathrm{p}}\right)+$ air + steam $\rightarrow$ carbon oxides + hydrogen + nitrogen

Dauenhauer et al. [24] found that the addition of steam at $\mathrm{S} / \mathrm{C}=4.5$ increased the equilibrium $\mathrm{H}_{2}$ selectivity by $30-$ $40 \%$. However, the observed $\mathrm{H}_{2}$ selectivity from glycerol departed from equilibrium for $\mathrm{C} / \mathrm{O}>1.0$, producing a maximum of $79 \%$ selectivity to $\mathrm{H}_{2}$. High selectivities to $\mathrm{H}_{2}$ were achieved by adjusting the fuel/air and fuel/steam feed ratios.

Swami et al. [25] conducted autothermal reforming at a steam-to-carbon ratio of 3 and an oxygen-to-carbon ratio of 0.3 in the range of $550-850{ }^{\circ} \mathrm{C}$ using the $\mathrm{Pd} / \mathrm{Ni} / \mathrm{Cu} / \mathrm{K}$ catalysts. Their results showed that the hydrogen yield during autothermal reforming was greater than that of steam reforming, though the hydrogen yield for both reactions increased with temperature. Douette et al. [26] performed a series of tests using a factorial experimental design to determine the effects of the operating parameters, including $\mathrm{C} / \mathrm{O}$ and $\mathrm{S} / \mathrm{C}$ ratio, and temperature. A 4.5 mol quantity of hydrogen was produced per mole of reagent-grade glycerin at oxygen to carbon ratio of $0, \mathrm{~S} / \mathrm{C}$ ratio of 2.2 , and temperature of $804{ }^{\circ} \mathrm{C}$. Initially, similar hydrogen yield was obtained when using crude glycerin, the by-product of biodiesel production. However, due to the catalyst deactivation and coke and deposit formation in the reformer, the hydrogen yield decreased quickly. This may be correlated with the possible contaminants, chloride and sodium cations, present in crude glycerin. 


\subsubsection{Aqueous-Phase Reforming}

The aqueous-phase reforming (APR) process was established by Cortright et al. [27] using platinum based catalysts and mild reaction conditions $\left(200-250{ }^{\circ} \mathrm{C}, 20-25\right.$ bar) for the production of hydrogen and light alkalines from oxygenated hydrocarbons. Lehnert et al. [28] used several platinum based catalysts for catalytic conversion of glycerol to hydrogen by APR. Their study indicated that the catalytic reaction selectivity to hydrogen increased with increasing particle size from $78 \%$ to $95 \%$ while the conversion of glycerol remained almost constant at $20 \%$. Furthermore, it was found that the mixture of $\gamma-, \delta$-, and $\theta$-phase can increase the hydrogen production to $7.6 \times 10^{-3} \mathrm{~mol} \mathrm{~min}^{-1} / \mathrm{g}_{\text {cat }}$, compared with pure $\gamma$-alumina $\left(1.2 \times 10^{-3} \mathrm{~mol} \mathrm{~min}^{-1} / \mathrm{g}_{\text {cat }}\right)$. Crude glycerol can also be used as starting material. However, the rate of hydrogen production was lower than for pure glycerol due to the impurities, such as $\mathrm{NaCl}$.

\subsubsection{Supercritical Water Reforming}

Supercritical water, defined as water that is heated and compressed at its critical temperature $\left(374^{\circ} \mathrm{C}\right)$ and pressure (22.1 MPa), is a promising medium for reforming of glycerol to produce hydrogen. Byrd et al. [29] selected $\mathrm{Ru} / \mathrm{Al}_{2} \mathrm{O}_{3}$ as the catalyst to generate hydrogen from glycerol by supercritical water reforming. Their experiments revealed that hydrogen yields increased directly with temperature and near-theoretical yield of $7 \mathrm{~mol}$ of hydrogen $/ \mathrm{mol}$ of glycerol could be obtained at dilute feed concentrations at $800{ }^{\circ} \mathrm{C}$. Also, it was found that up to $40 \mathrm{wt} \%$ glycerol in the starting material could be completely gasified.

\subsection{Glycerol to Ethanol}

Ethanol can not only be utilized as raw material and a supplement to gasoline, but as the reactant for biodiesel production. The feasibility of generating ethanol from glycerol, the by-product of biodiesel production, will benefit the biodiesel industry. Many researchers showed strong interest in this area. Jarvis et al. [30] successfully obtained ethanol by glycerol fermentation with a Klebsiella planticola strain isolated from red deer. It was reported that glycerol dissimilation by Klebsiella planticola led to the production of ethanol at levels of $30 \mathrm{mmol}^{-1}$. As comparison, Temudo et al. [31] investigated the glycerol fermentation by mixed cultures at alkaline $\mathrm{pH}$. Their studies indicated that ethanolformate and 1,3-propanediol-acetate were the primary catabolic product formation pathways. The substrate limiting conditions were the main affecting factors for ethanol formation. Under these conditions, up to $60 \%$ of the substrate carbon was converted into ethanol and formate in a 1:1 ratio. Dharmadi et al. [32] reported that Escherichia coli can anaerobically ferment glycerol in a $\mathrm{pH}$-dependent manner. According to the authors, within $84 \mathrm{~h}$ of active growth, glycerol was almost completely consumed, achieving a maximum cell concentration of $486.2 \mathrm{mg} / \mathrm{L}$. Ethanol accounted for about $80 \%$ (molar basis) of the products. $\mathrm{CO}_{2}$ is necessary in this fermentation process in order for glycerol fermentation to proceed. This study revealed that at acid $\mathrm{pH}$ conditions, in which the availability of of $\mathrm{CO}_{2}$ required for cell growth could be facilitated, glycerol fermentation could proceed optimally. Ito et al. [33] evaluated the possibility of using Enterobacter aerogenes HU-101 to produce hydrogen and ethanol from glycerol- containing wastes discharged after biodiesel production. It was found that using synthetic medium could increase the rate of glycerol utilization. When diluted to $80 \mathrm{Mm}$ glycerol with the synthetic medium, glycerol was completely consumed after $24 \mathrm{~h}$, yielding hydrogen at $0.89 \mathrm{~mol} / \mathrm{mol}-$ glycerol and ethanol at $1.0 \mathrm{~mol} / \mathrm{mol}$-glycerol. Without nutrients addition, even after $48 \mathrm{~h}$, glycerol was not completely consumed and no growth was observed. The addition of both yeast extract and tryptone to the synthetic medium could effectively increase the rates of hydrogen and ethanol production. At the range of dilutions tested, methanol showed no negative effect, while the high salinity of the medium with crude glycerol from biodiesel production could inhibit the cell growth. This explained why with the same packed-bed reactor, the maximum rate of hydrogen and ethanol production was higher for pure glycerol $(0.80$ $\mathrm{mol} / \mathrm{mol}$-glycerol) than the crude glycerol. However, when applying the porous ceramics as a support material to fix cells in the reactor, ethanol yield of $0.85 \mathrm{~mol} / \mathrm{mol}$-glycerol could be obtained when using crude glycerol.

\subsection{Glycerol to Additives}

Glycerol can also be used to produce glycerol-based additives which can improve biodiesel properties. García et al. [34] conducted a study of a new oxygenate synthesized from crude glycerin as a biodiesel additive. According to the authors, the new acetal (2,2-dimethyl-1,3-dioxolan-4-yl) methyl acetate obtained by reacting acetal 1 (obtained by mixing glycerin and acetone with p-toluenesulfonic acid monohydrate. The reaction mixture was heated to reflux for $16 \mathrm{~h}$ ) with acetic anhydride in triethylamine solution at room temperature for $4 \mathrm{~h}$ could improve biodiesel viscosity and meet the flash point and oxidation stability requirements as well. Glycerol can also be blended with glycerol based coproducts, such as propanediol and propanol and gasoline as oxygenates. Fernando et al. [35] reported the possibility of using glycerol and its derivatives with gasoline as an automotive fuel. Among the blending samples, the mixture of glycerol (6 vol\%), propanol (60 vol\%), and gasoline has an energy value of $33.25 \mathrm{MJ} / \mathrm{kg}$ and a motor octane number of greater than 100. Glycerol can also find new applications in lubricant manufacturing without very expensive purification process according to Jerzykiewicz et al. [36]. They reported that crude glycerol fraction showed remarkable antioxidant and anticorrosive properties determined by electron paramagnetic resonance spectroscopy and Herbert method, respectively. The authors attributed this to the fact that most phenolic antioxidants present in oils are transferred to the glycerol fraction during esterification.

\section{GLYCEROL FROM SECOND-GENERATION BIODIESEL PRODUCTION}

It is important to keep in mind that the glycerol discussed above is the by-product of first-generation of biodiesel production and its purity is low, which makes further conversion to value-added products more difficult. The firstgeneration biodiesel production has generated a lot of controversy due to their impact on global food markets and food security. As comparison, second-generation biodiesel production, which uses non-edible oil, such as jatropha, microalgae, as feedstock, has attracted much attention since it can prevent the competition with human food. In this 
process, enzyme is mostly preferred as catalyst. This will make the recovery of glycerol much easier and higher purity glycerol could be achieved due to the fact that free fatty acid in the feedstock can also be converted to biodiesel and no soap is generated. This will increase the applications for the glycerol, such as uses as cosmetics, though further biorefinery work is still needed. Therefore, the related impurity problem for the glycerol will be minimized and even eliminated.

\section{OUTLOOK AND CONCLUSIONS}

As discussed in this Minireview, the availability of crude glycerol will increase in the next years due to the tremendous growth in the production of biodiesel worldwide. The flood of glycerol presents challenges to traditional glycerolproducing plants. On the other hand, this can also offer an excellent opportunity to produce value-added products from glycerol because of its abundance and low pricing. At present, glycerol is already serving as a highly versatile feedstock for the production of a variety of high-value chemicals, polymers, and fuels, including citric acid, lactic acid, DHA, 1,3-PD, DCP, acrolein, hydrogen, ethanol and additives, etc. This can save biodiesel production cost and benefit the biodiesel industry.

The conversion of glycerol to 1,3-PD is promising, especially when using enzymatic approach. 1,3-PD seems to exhibit a strong tendency to become a new platform chemical in polyester chemistry.

The conversion of crude glycerol to hydrogen is important since the demand for hydrogen is growing due to the technological advancements in fuel cell industry. The impurities in the crude glycerol can cause a catalyst deactivation, thus impeding catalyst performance for hydrogen production. However, with the development of heterogeneous catalyst and enzymatic catalyst for biodiesel production, the purity of crude glycerol will be improved.

In addition to the above-mentioned chemicals, researchers are focusing on the algal biomass fermentation by using glycerol as carbon source, which will definitely benefit the biofuels market since algal biofuels appear to be the only current renewable source that could meet the global demand for transport fuels.

Furthermore, with the advent of second-generation biodiesel production, high purity glycerol could be obtained by using enzyme catalyst, which will further increase the applications of glycerol.

\section{ACKNOWLEDGEMENT}

The authors wish to acknowledge Piedmont Biofuels Industrial for financing this Minireview study.

\section{REFERENCES}

[1] Wang, L.; Du, W.; Liu, D.H.; Li, L.L.; Dai, N.M. Lipase-catalyzed biodiesel production from soybean oil deodorizer distillate with absorbent present in tert-butanol system. J. Mol. Catal. B-Enzyme, 2006, 43, 29-32.

[2] Rymowicz, W.; Rywińska, A.; Żarowska, B.; Juszczyk, P. Citric acid production from raw glycerol by acetate mutants of yarrowia lipolytica. Chem. Pap., 2006, 60(5), 391-394.

[3] Imandi, S.B.; Bandaru, V.R.; Somalanka, S.R.; Garapati, H.R. Optimization of medium constituents for the production of citric acid from byproduct glycerol using Doehlert experimental design. Enzyme Microb. Tech., 2007, 40, 1367-1372.

[4] Datta, R.; Henry, M. Lactic acid: recent advances in products, processes and technologies- a review. J. Chem. Technol. Biotechnol., 2006, 81, 1119-1129.

[5] Hong, A.A.; Cheng, K.K.; Peng, F.; Zhou, S.; Sun, Y.; Liu, C.M.; Liu, D.H. Strain isolation and optimization of precess parameters for bioconversion of glycerol to lactic acid. J. Chem. Technol. Biotechnol., 2009, 84, 1576-1581.

[6] Ciriminna, R.; Palmisano, G.; Pina, C.D.; Rossi, M.; Pagliaro, M. One-pot electrocatalytic oxidation of glycerol to DHA Tetrahedron Lett., 2006, 47, 6993-6995.

[7] Pyle, D.J.; Garcia, R.A.; Wen, Z.Y. Producing docosahexaenoic acid (DHA)-rich algae from biodiesel- derived crude glycerol: effects of impurities on DHA production and algal biomass composition. J. Agric. Food Chem., 2008, 56, 3933-3939.

[8] Mu, Y.; Teng, H.; Zhang, D.J.; Wang, W.; Xiu, Z.L. Microbial production of 1,3-propanediol by klebsiella pneumoniae using crude glycerol from biodiesel preparations. Biotechnol. Lett., 2006, 28(21), 1755-1759.

[9] Nemeth, A.; Sevella, B. Development of a new bioprocess for production of 1,3-propanediol I.: modeling of glycerol bioconversion to 1,3-propanediol with klebsiella pneumoniae enzymes. Appl. Biochem. Biotechnol., 2008, 144(1), 47-58.

[10] Rehman, A.U.; Wijesekara, S.; Nomura, N.; Sato, S.; Matsumura M. Pretreatment and utilization of raw glycerol from sunflower oil biodiesel for growth and 1,3-propanediol production by clostridium butyricum. J. Chem. Technol. Biotechnol., 2008, 83, 1072-1080.

[11] Abu-El-Haj, S.; Bogusz, M.J.; Ibrahim, Z.; Hassan, H.; Tufail, M.A. Rapid and simple determination of chloropropanols (3MCPD and 1,3-DCP) in food products using isotope dilution GCMS. Food Control, 2007, 18, 81-90.

[12] Ma, L.; Zhu, J.W.; Yuan, X.Q.; Yue, Q. Synthesis of epichlorohdrin from dichloropropanols kinetics aspects of the process. Chem. Eng. Res. Des., 2007, 85(A12), 1580-1585.

[13] Luo, Z.H.; You, X.Z.; Li, H.R. Direct preparation kinetics of 1,3dichloro-2-propanol from glycerol using acetic acid catalyst. Ind. Eng. Chem. Res., 2009, 48, 446-452.

[14] Lee, S.H.; Park, D.R.; Kim, H.; Lee, J.; Jung, J.C.; Woo, S.Y.; Song, W.S.; Kwon, M.S.; Song, I.K. Direct preparation of dichloropropanol (DCP) from glycerol using heteropolyacid (HPA) catalysts: A catalyst screen study. Catal. Commun., 2008, 9, 19201923.

[15] Watanabe, M.; Iida, T.; Aizawa, Y.; Aida, T.M.; Inomata, H. Acrolein síntesis from glycerol in hot-compressed water. Bioresour. Technol., 2007, 98, 1285-1290.

[16] Yan, W.; Suppes, G.J. Low-pressure packed-bed gas-phase dehydration of glycerol to acrolein. Ind. Eng. Chem. Res., 2009, 48, 3279-3283

[17] Wang, X.D.; Li, S.R.; Wang, H.; Liu, B.; Ma, X.B. Thermodynamic analysis of glycerin steam reforming. Energ. Fuel., 2008, 22, 4285-4291.

[18] Adhikari, S.; Fernando, S.; Haryanto, A. A comparative thermodynamic and experimental análisis on hydrogen production by steam reforming of glicerina. Energ. Fuel., 2007, 21, 23062310.

[19] Slinn, M.; Kendall, K.; Mallon, C.; Andrews, J. Steam reforming of biodiesel by-product to make renewable hydrogen. Bioresour. Technol., 2008, 99, 5851-5858.

[20] Adhikari, S.; Fernando, S.D.; Haryanto, A. Hydrogen production from glycerin by steam reforming over nickel catalysts. Renew. Energy, 2008, 33, 1097-1100.

[21] Iriondo, A.; Barrio, V.L.; Cambra, J.F.; Arias, P.L.; Güemez, M.B.; Navarro, R.M.; Sánchez-Sánchez, M.C.; Fierro, J.L.G. Hydrogen production from glycerol over nickel catalysts supported on $\mathrm{Al}_{2} \mathrm{O}_{3}$ modified by $\mathrm{Mg}, \mathrm{Zr}$, Ce or La. Top. Catal., 2008, 49, 46-58.

[22] Zhang, B.C.; Tang, X.L.; Li, Y.; Xu, Y.D.; Shen, W.J. Hydrogen production from steam reforming of ethanol and glycerol over ceria-supported metal catalysts. Int. J. Hydrogen Energy, 2007, 32, 2367-2373.

[23] Hirai, T.; Ikenaga, N.O.; Miyake, T.; Suzuki, T. Production of hydrogen by steam reforming of glycerin on ruthenium catalyst. Energ. Fuel., 2005, 19, 1761-1762.

[24] Dauenhauer, P.J.; Salge, J.R.; Schmidt, L.D. Renewable hydrogen by autothermal steam reforming of volatile carbohydrates. $J$. Catal., 2006, 244, 238-247. 
[25] Swami, S.M.; Abraham, M.A. Integrated catalytic process for conversion of biomass to hydrogen. Energ. Fuel., 2006, 20, 26162622.

[26] Douette, A.M.D.; Turn, S.Q.; Wang, W.Y.; Keffer, V.I. Experimental investigation of hydrogen production from glycerin reforming. Energ. Fuel., 2007, 21, 3499-3504.

[27] Cortright, R.D.; Davda, R.R.; Dumesic, J.A. Hydrogen from catalytic reforming of biomass-derived hydrocarbons in liquid water. Nature, 2002, 418, 964-967.

[28] Lehnert, K.; Claus, P. Influence of Pt particle size and support type on the aqueous-phase reforming of glycerol. Catalysis Communications, 2008, 9, 2543-2546.

[29] Byrd, A.J.; Pant, K.K.; Gupta, R.B. Hydrogen production from glycerol by reforming in supercritical water over $\mathrm{Ru} / \mathrm{Al}_{2} \mathrm{O}_{3}$ catalyst. Fuel, 2008, 87, 2956-2960.

[30] Jarvis, G.N.; Moore, E.R.B.; Thiele, J.H. Formate and ethanol are the major products of glycerol fermentation produced by a klebsiella planticola strain isolated from red deer. J. Appl. Microbiol., 1997, 83, 166-174.
[31] Temudo, M.F.; Poldermans, R.; Kleerebezem, R.; Loosdrecht, M.C.M. Glycerol fermentation by (open) mixed cultures: A chemostat study. Biotechnol. Bioeng., 2008, 100(6), 1088-1098.

[32] Dharmadi, Y.; Murarka, A.; Gonzalez, R. Anaerobic fermentation of glycerol by escherichia coli: a new platform for metabolic engineering. Biotechnol. Bioeng., 2006, 94(5), 821-829.

[33] Ito, T.; Nakashimada, Y.; Senba, K.; Matsui, T.; Nishio, N. Hydrogen and etanol production from glycerol-containing waste discharged alter biodiesel manufacturing process. J. Biosci. Bioeng., 2005, 100(3), 260-265.

[34] García, E.; Laca, M.; Pérez, E.; Garrido, A.; Peinado, J. New class of acetal derived from glicerina as a biodiesel fuel component Energ. Fuel., 2008, 22, 4274-4280.

[35] Fernando, S.; Adhikari, S.; Kota, K.; Bandi, R. Glycerol based automotive fuels from future biorefineries. Fuel, 2007, 86, 28062809.

[36] Jerzykiewicz, M.; Cwielag, I.; Jerzykiewicz, W. The antioxidant and anticorrosive properties of crude glycerol fraction from biodiesel production. J. Chem. Technol. Biotechnol., 2009, 84, 1196-1201.

(C) Fan et al.; Licensee Bentham Open.

This is an open access article licensed under the terms of the Creative Commons Attribution Non-Commercial License (http://creativecommons.org/licenses/by$\mathrm{nc} / 3.0 /$ ) which permits unrestricted, non-commercial use, distribution and reproduction in any medium, provided the work is properly cited. 